\title{
State of art of cooling method for dry machining
}

\author{
Kaaliarasan Ramachandran ${ }^{1, *}$, Balakumaran Yeesvaran ${ }^{1}$, Kumaran $_{\text {Kadirgama }}{ }^{1,2}$, \\ Devarajan Ramasamy ${ }^{1,2}$, Saiful Anwar Che Ghani ${ }^{1}$ and Keeran Anamalai ${ }^{1}$ \\ ${ }^{1}$ Faculty of Mechanical Engineering, Universiti Malaysia Pahang, 26600 Pekan, Pahang, Malaysia \\ ${ }^{2}$ Automotive Engineering Centre, Universiti Malaysia Pahang, 26600 Pekan, Pahang, Malaysia
}

\begin{abstract}
The usage of cutting fluid in the machining operations will not only poses health risk to the workers but also creates environmental challenges associated with fluid treatment and disposal. The objective of this review paper is to identify present cooling method in dry machining and novel feature than can be included in the cooling system for a better heat removal which tend to increase machining performance. From the review study, it shows that cooling method by internal manner is most widely been researched because researcher believes that it has a promising future in adaptive machining to produce a contamination free products which supports the green manufacturing concept. The suggested novel feature is ecologically desirable and it will become as a necessity for improving the performance of dry machining in the near future.
\end{abstract}

\section{Introduction}

Machining can be performed under three different condition; wet machining, near dry machining and dry machining. Traditionally, in wet machining, cutting fluid is used to reduce cutting temperature, reduce cutting force, minimize formation of buildup edge and improve tool life $[1,2]$. In USA alone, volume of cutting fluid that is been discharged is nearly 115 million liters per year [3] and cost to retreat the cutting fluid with additive is USD 15 per gallon [3]. Study in year 1994 at Germany, records usage of cutting fluid is 1.15 million which is responsible of $7 \%-17 \%$ for cutting fluid and $2 \%$ to $4 \%$ for cutting tool from overall cost [4]. This clearly shows that the cost of cutting fluid exceeds the cost of cutting tool and overhead cost [5]. Meanwhile, cutting fluid also creates environmental issues and causes health injuries to humans $[6,7]$. Exposure of cutting fluid causes skin cancer and evaporation of cutting fluid at cutting zone is dangerous to human respiratory system [1, 6]. Cutting fluid cannot be used for long term as it is tend to wear out after mixing with the chips [4]. Wet machining decreases the cutting fluid efficiency because of two factors; limitation of cutting fluid to reach cutting zone and chip movement during machining $[4,8]$. Near dry machining has only small effectiveness in cooling cutting tool and ineffective to machine difficult materials [4].

In these cases, dry machining is much more preferable as it saves cost, environmentally friendly and does not harm the human health [5]. The main limitation in dry machining is the heat generation at cutting tool specifically; cutting zone. During machining, friction and

\footnotetext{
* Corresponding author: kaaliarasan@gmail.com
} 
chip deformation at cutting interface causes thermal load which causes high temperature at cutting tool $[1,2]$. High temperature is because of the high friction and adhesion formation at cutting tool [1]. Heat generated during machining causes two changes in the cutting tool; reduces mechanical and wear resistance [4]. It is proven that the deformation and friction converts $99 \%$ input energy to heat [9]. This leads to the tool wear subsequently which reduces the tool's life span [2]. Formation of tool wear causes the workpiece subjected to poor surface roughness and less dimensional accuracy $[1,2]$. There are two methods to control the heat generated during machining; limitation of cutting parameter and usage of cutting fluid [4]. Every combination of cutting tool and workpiece has its own optimum cutting parameter to produce good surface finish product and prolongs the tool life. But in the first method the work productivity is affected because of the machining limitation [4]. In the second method, cutting fluid is used to reduce the cutting zone temperature. Meanwhile, friction coefficient in dry machining can be reduced by two methods; coating layer at cutting tool and material selection of cutting tool [10]. By reducing temperature at cutting tool during dry machining operating, performance of the machining can be increased. Dry machining will only be acceptable if the machining performance results exceeds or equals the performance of the wet machining [4].

Researchers are finding alternate solution to eliminate the usage of cutting fluid and encourage dry machining method which supports the green manufacturing concept $[2,4]$. Some of the cooling method for dry machining are internally cooled, indirect cooling, solid lubricant and heat pipe technology [2, 4, 6, 10-12]. For time being, internal cooling system is the most promising cooling system to improve dry machining's performance $[1,13]$. Indirect cooling which uses cryogen is effective but very costly [6]. Heat removal by using heat pipe is more attractive as no external flow source and external power supply is used in the cooling system [12]. This paper is about the cooling method and introduces novel features to improve existing dry machining performance.

\section{Cooling method in dry machining to improve machining performance}

Cooling a cutting tool by internal manner is the most effective solution for dry machining [2]. L. E. A. Sanchez [4] come out with an idea to make a chamber in the tool holder in which cutting fluid will be channeled through the inlet and exits through the outlet. Cutting tool will be placed on top of the cavity whereby the heat generated during machining will be carried away by the cutting fluid which flows inside the chamber of tool holder [4]. The heated cutting fluid is then carried away to condenser. Copper board which has a high value of thermal conductivity is placed in between to increase the heat transfer rate. Copper board addition will promote for a better heat transfer rate since it has large surface area. The main challenge in this design is to make the internal chamber inside the tool holder. The schematic diagram of the internally cooled tool for turning as shown in Figure 1.

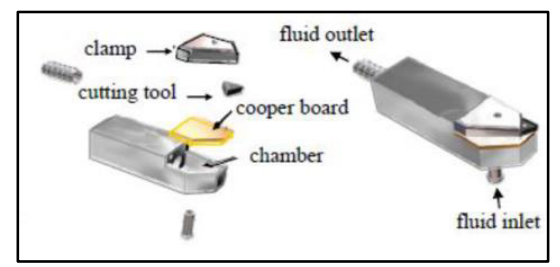

Fig. 1. Assembly of internally cooled tool for turning [4]. 
Sun [1] approach by inverting own cooling method by combination of "bottle-cap insert" and chambered adaptor. Cutting tool is designed and machined to have a "bottle-cap insert" look as shown in Figure 2(a). Adaptor is designed with chamber and two micro holes at the corner as shown in Figure 2(b). As the cutting fluid is channeled through the micro hole, the chambered section in the adaptor forms a cooling tube with a triangle section. By channeling the cutting fluid at the tip of the cutting tool, the heat transfer rate increases and improves the tool life. This type of cooling system is most suitable for customized square shape cutting tool. Sun [1] proves that the internal cooling actually helps to decrease the cutting temperature which improves the tool life. The diameter of the internal structure is the most important factor when designing an internal cooling system [1, 13].

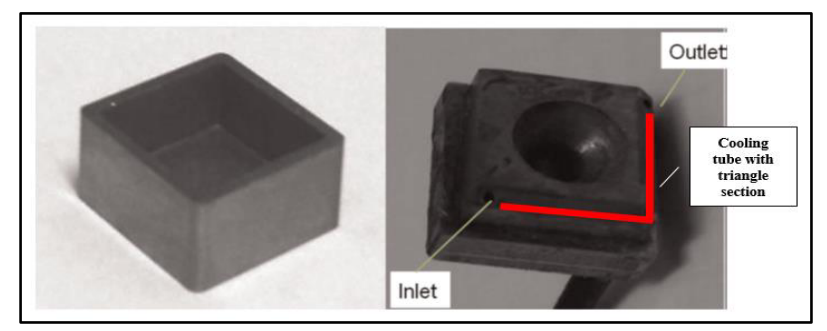

(a)

(b)

Fig. 2(a). Final look of "Bottle-cap insert" [1].

Fig. 2(b). Chambered adaptor with micro holes which represent inlet and outlet of cutting fluid [1].

Y Isik [14] finds that heat transfer can be increased by placing the internal cooling system closer to the cutting tool [14]. Internally cooled tool (ICTool) is a reliable achievement in the internally cooling system. Pure cooling water is used as the cutting fluid because it has high heat capacity value and does not pollute the environment $[13,14]$. In this design, as shown in Figure 3,2mm holes of cooling channel is made at the pocket of tool holder. Cutting tool will be placed at the top of the tool pocket to directly absorb the heat transfer during machining [14]. Cutting fluid will be supplied to the cooling channel through the inlet and outlet of the pipe situated at the sides of the cutting tool. Additives are included in the cooling pure water to prevent corrosion on the tool holder [13, 14].

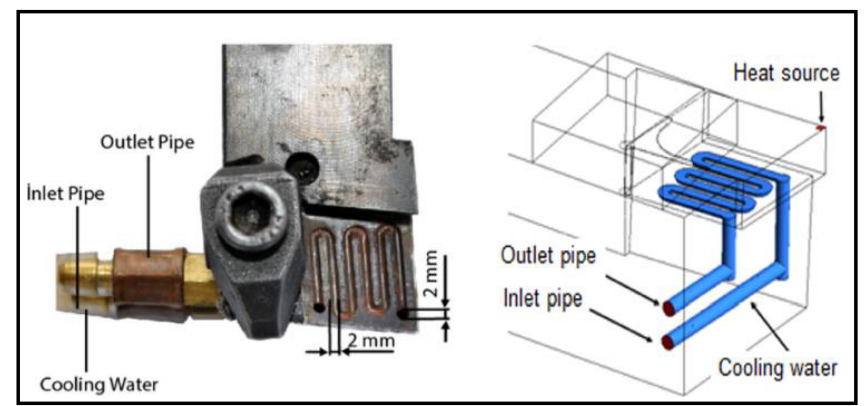

Fig. 3. Parts and exploded view of Internally cooled tool (ICTool) [14].

Another approach of the design is by using cryogen as an indirect cooling method of cutting tool. Thermal conductor plate is placed between the cutting tool and tool holder groove to increase the heat removal. The indirect cryogen is supplied to the cutting tool by having a modified micro cooling channel at the sides of the cutting tool [7]. Fins can be added inside of the grooves, to increase the heat transfer efficiency. The required flow rate of cryogen to cool down the cutting tool during the machining is less than $1 \%$ compared to the amount of the standard cutting fluid required to cool the same insert during the same 
machining operation [2, 7]. Figure 4 shows the schematic diagram of indirect cooling system in the cutting tool.

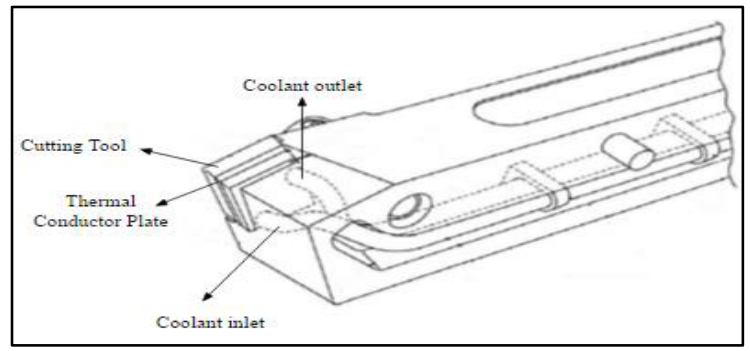

Fig. 4. Parts and exploded view of indirect cooling system in cutting tool [7].

Liang [12] describes that the usage of heat pipe as a cooling system to reduce the thermal elongation of tool holder which reduces the tool wear. Heat pipe is attached to the tip of the cutting tool. A modified cutting tool with a hollow structure is made to hold the heat pipe at the sides. Placement of the heat pipe absorbs the heat generated during machining. This cooling does not require any external flow medium or power source. [12] Heat transfer efficiency of the cooling system can be increased by considering the lengths, diameters, vacuums and materials of the heat pipe [12]. Figure 5 shows the placement of the heat pipe at the cutting tool.

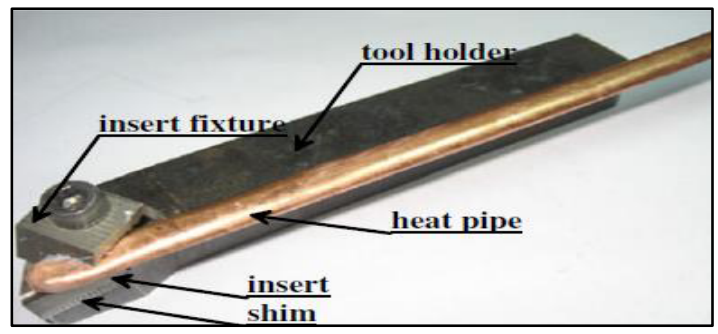

Fig. 5. Placement of heat pipe on cutting tool [12].

Jianxin [15] suggests the use of a solid lubricant to encounter the friction coefficient problem during machining. Micro hole is made at the cutting tool to place the solid lubricant onto it. Micro hole can be made at two locations; rake face or flank face. Solid lubricants at the rake face results in a lower flank wear than solid lubricant at flank face [15]. Studies show that solid lubricant placed at the rake face records the lowest friction coefficient and least tool wear value [10,15]. Figure 6 shows the self-lubricated tool system in the dry machining.

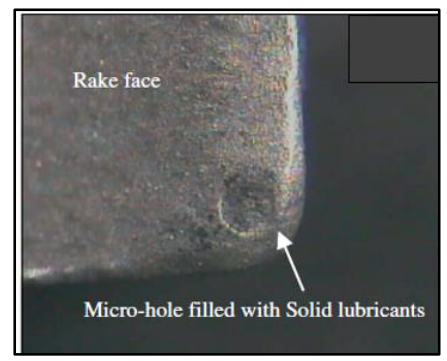

Fig. 6. Location of micro hole in self-lubricated tool system [15]. 
Solid lubricant, Calcium Difluoride $\left(\mathrm{CaF}_{2}\right)$ will be included in fabricating the ceramic cutting tool by hot pressing process [10]. About $10 \%$ of solid lubricant is included into the ceramic matrix [10]. Friction coefficient at tool-chip interface can be reduced as the solid lubricant produces self-lubricating film on it [10]. The formation of the self-lubricating film as shown in Figure 7 smears on the cutting tool reduces friction coefficient, tool wear and increases life span of tool [10]. This can be achieved as easy shearing along basal plane of the hexagonal crystalline structure at the ceramic matrix [10].

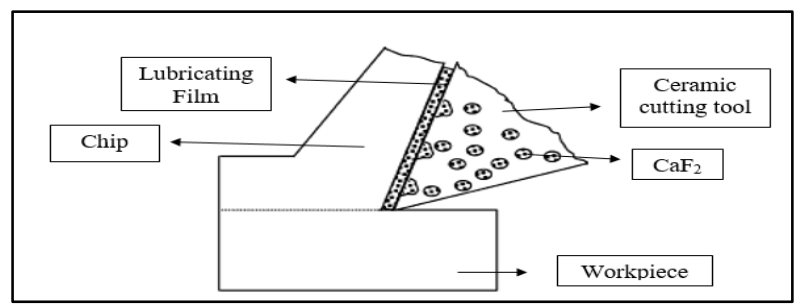

Fig. 7. Location formation of lubricating film on tool-chip interface [10].

\section{Comparison of cooling methods for dry machining}

Tables 1 and 2 show a complete comparison of cooling system for dry machining. Generally, the main drawback of internally cooled cooling method is the complex internal cooling design which is difficult to fabricate but it is very efficient in heat absorption during machining. Meanwhile, indirect cooling is the most efficient in heat removal but it requires high setup cost. Cooling by solid lubricant is effective but the strength of the cutting tool need to sacrificed. Finally, heat pipe technology is an innovative cooling method without the presence of power supply but it has low heat transfer effectiveness.

Table 1. Complete comparison of cooling system for dry machining (internally cooled).

\begin{tabular}{|c|c|c|c|c|}
\hline $\begin{array}{l}\text { Cooling } \\
\text { Method }\end{array}$ & Design & $\begin{array}{l}\text { Cooling } \\
\text { Medium }\end{array}$ & Pro & Con \\
\hline \multirow{3}{*}{$\begin{array}{c}\text { Internally } \\
\text { cooled }\end{array}$} & $\begin{array}{l}\text { Internally } \\
\text { cooled tool } \\
\text { for turning }\end{array}$ & $\begin{array}{c}\text { R-123 } \\
\text { cutting fluid } \\
{[4]}\end{array}$ & $\begin{array}{l}\text { - Simple and low cost [4] } \\
\text { - Efficient heat exchanger } \\
\text { [4] } \\
\text { - Improvement in the heat } \\
\text { removal [4] } \\
\text { - Environmental and } \\
\text { economic advantages } \\
\text { [4] }\end{array}$ & $\begin{array}{l}\text { - Complex design } \\
\text { - Difficult to } \\
\text { machine } \\
\text { - HCFC leakage } \\
\text { pollutes } \\
\text { environment [4] }\end{array}$ \\
\hline & $\begin{array}{l}\text { Internally } \\
\text { cooled } \\
\text { "bottle- } \\
\text { cap" smart } \\
\text { cutting tool }\end{array}$ & $\begin{array}{c}\text { Pure water } \\
\text { [1] }\end{array}$ & $\begin{array}{l}\text { - Low cost and easy to } \\
\text { use [1] } \\
\text { - Substantial cost } \\
\text { reduction [1] } \\
\text { - Friendly environmental } \\
\text { machining [1] }\end{array}$ & $\begin{array}{l}\text { - Custom made } \\
\text { cutting tool } \\
\text { - Time consuming } \\
\text { to produce } \\
\text { cutting tool }\end{array}$ \\
\hline & $\begin{array}{l}\text { Internally } \\
\text { Cooled } \\
\text { Tool } \\
\text { (ICTool) }\end{array}$ & $\begin{array}{c}\text { Cooled pure } \\
\text { water [14] }\end{array}$ & $\begin{array}{l}\text { - Green cooling method } \\
\text { [14] } \\
\text { - Efficient in heat } \\
\text { removal [14] } \\
\text { - Better surface quality } \\
\text { and extended tool life } \\
\text { [14] }\end{array}$ & $\begin{array}{l}\text { - Complex cooling } \\
\text { system } \\
\text { - Difficult to } \\
\text { machine cooling } \\
\text { channel }\end{array}$ \\
\hline
\end{tabular}


Table 2. Comparison of dry machining cooling system for other methods.

\begin{tabular}{|c|c|c|c|c|}
\hline $\begin{array}{l}\text { Cooling } \\
\text { Method }\end{array}$ & Design & $\begin{array}{l}\text { Cooling } \\
\text { Medium }\end{array}$ & Pro & Con \\
\hline $\begin{array}{l}\text { In direct } \\
\text { cooling }\end{array}$ & $\begin{array}{c}\text { Indirect } \\
\text { cooling of } \\
\text { cutting tool }\end{array}$ & Cryogen [7] & $\begin{array}{l}\text { - High heat removal } \\
\text { capacity [4] } \\
\text { - High heat transfer } \\
\text { effectiveness [7] } \\
\text { - Decreases the usage of } \\
\text { the cutting fluid [2] }\end{array}$ & $\begin{array}{l}\text { - Complex micro } \\
\text { cooling channel } \\
\text { design } \\
\text { - High setup cost } \\
\text { [4] } \\
\text { - Cryogen is } \\
\text { expensive and } \\
\text { not reusable [16] }\end{array}$ \\
\hline \multirow{2}{*}{$\begin{array}{c}\text { Solid } \\
\text { lubricant }\end{array}$} & $\begin{array}{l}\text { Self- } \\
\text { lubricated } \\
\text { tool in dry } \\
\text { machining }\end{array}$ & $\begin{array}{l}\text { Molybdenm } \\
\text { disulfide } \\
\left(\mathrm{MoS}_{2}\right)[15]\end{array}$ & $\begin{array}{l}\text { - } \text { Reduces friction } \\
\text { coefficient }[10,15,17] \\
\text { - Controls heat generation } \\
\text { [17] } \\
\text { - Improves flank wear } \\
\text { [15] }\end{array}$ & $\begin{array}{l}\text { - Reduces physical } \\
\text { property and } \\
\text { strength of } \\
\text { cutting tool }\end{array}$ \\
\hline & $\begin{array}{l}\text { Self-made } \\
\text { cutting tool } \\
\text { with solid } \\
\text { lubricants }\end{array}$ & $\begin{array}{c}\text { Calcium } \\
\text { Difluoride } \\
\left(\mathrm{CaF}_{2}\right)[10]\end{array}$ & $\begin{array}{l}\text { - Improves tribology [10, } \\
18-20] \\
\text { - Usable in high } \\
\text { temperature applications } \\
{[10]}\end{array}$ & $\begin{array}{l}\text { - Study on the } \\
\text { solid lubricant } \\
\text { before fabricating } \\
\text { the cutting tool. }\end{array}$ \\
\hline $\begin{array}{l}\text { Heat pipe } \\
\text { technology }\end{array}$ & $\begin{array}{l}\text { Dry turning } \\
\text { assisted by } \\
\text { heat pipe } \\
\text { cooling }\end{array}$ & $\begin{array}{l}\text { Heat pipe: } \\
\text { Height: } \\
4 \mathrm{~mm} \\
\text { Length: } \\
\text { 150mm } \\
\text { Thickness: } \\
0.65 \mathrm{~mm} \\
{[12]}\end{array}$ & $\begin{array}{l}\text { - No external power } \\
\text { supply [12] } \\
\text { - Reduces the thermal } \\
\text { elongation of tool holder } \\
\text { [12] } \\
\text { - Zero usage of cooling } \\
\text { medium [12] }\end{array}$ & $\begin{array}{l}\text { - Low heat transfer } \\
\text { effectiveness [7] } \\
\text { - Groove need to } \\
\text { be made at the } \\
\text { cutting tool, } \\
\text { which will reduce } \\
\text { the mechanical } \\
\text { strength. }\end{array}$ \\
\hline
\end{tabular}

\section{Future of cooling system to improve performance of dry machining}

In the near future, the cooling system for the dry machining can be designed with more complex structure with the developed technologies like the 3D printers and Selective Laser Melting (SLM). Conversely, new type of cutting fluid with higher heat capacity can be used to accelerate the heat transfer rate. It will be a positive impact to the environment and green technology if biodegradable cutting fluid can be used for the cooling purposes. Besides, it is very possible with the development of Nano cellulose. Absence of cutting fluid in dry machining causes the chips not to be washed away. An integrated air system can be installed together with the cooling system at the tool holder to clear away the chips. This is feasible as most of the laboratories are equipped with air compression system in the recent era. Temperature and force can be monitored during machining with the innovation of the smart cutting tool. Smart cutting tool which is integrated with sensors can be used to predict the changes in the cutting zone and determine the life span of the cutting tool.

\section{Conclusions}

Dry machining with a proper cooling method can be used to achieve better machining performances than the wet machining by maximizing the heat removal rate, focusing heat 
removal at the tip of the cutting tool. From the review, internal cooling method is most widely researched compared to other cooling methods. This is because of the easiness and record promising results of the internal cooling method result compared to the other methods. Researches and developments of cooling method need to be widen up to improve the dry machining in term of the surface roughness, tool wear and life span of the cutting tool. Development of the cooling method is aided by the modern technologies and innovations all over the world.

The authors would like to be obliged to Universiti Malaysia Pahang for providing laboratory facilities and financial assistance under project no. RDU1403134.

\section{References}

1. X. Sun, R. Bateman, K. Cheng, S. Ghani, Design and analysis of an internally cooled smart cutting tool for dry cutting. Proceedings of the Institution of Mechanical Engineers, Part B: Journal of Engineering Manufacture 226, 585-591 (2012).

2. A. Kromanis, G. Pikurs, , G. Muiznieks, K. Kravalis, V. Gutakovskis, Design of internally cooled tools for dry cutting. in 9th International DAAAM Baltic Conference: INDUSTRIAL ENGINEERING 24-26 (2014).

3. S.Y. Hong,, M. Broomer, Economical and ecological cryogenic machining of AISI 304 austenitic stainless steel. Clean Products and Processes 2, 157-166 (2000).

4. L.E. Sanchez, V.L. Scalon, G.G. Abreu, Cleaner machining through a toolholder with internal cooling. in 3rd International Workshop Advances in cleaner production. Brazil (2011).

5. P. Sreejith, B. Ngoi, Dry machining: machining of the future. Journal of materials processing technology 101, 287-291 (2000).

6. N. Dhar, S. Paul, A. Chattopadhyay, The influence of cryogenic cooling on tool wear, dimensional accuracy and surface finish in turning AISI 1040 and E4340C steels. Wear 249, 932-942 (2001).

7. J.C. Rozzi, W. Chen, E.E. Archibald, Indirect cooling of a cutting tool. (Google Patents, 2011).

8. K. Seah, X. Li, K. Lee, The effect of applying coolant on tool wear in metal machining. Journal of materials processing technology 48, 495-501 (1995).

9. A. Balaji, G. Sreeram, I. Jawahir, E. Lenz, The effects of cutting tool thermal conductivity on tool-chip contact length and cyclic chip formation in machining with grooved tools. CIRP Annals-Manufacturing Technology 48, 33-38 (1999).

10. D. Jianxin, C. Tongkun, Y. Xuefeng, L. Jianhua, Self-lubrication of sintered ceramic tools with CaF 2 additions in dry cutting. International Journal of Machine Tools and Manufacture 46, 957-963 (2006).

11. A. Kromanis et al. Design of Internally Cooled Tools for Turning. Rigas Tehniskas Universitates Zinatniskie Raksti 35, 93 (2013).

12. L. Liang, Y. Quan, Z. Ke, Investigation of tool-chip interface temperature in dry turning assisted by heat pipe cooling. The International Journal of Advanced Manufacturing Technology 54, 35-43 (2011).

13. B.C. Ghani, S. Anwar, Brunel University School of Engineering and Design PhD Theses (2013).

14. Y. Isik, Using internally cooled cutting tools in the machining of difficult-to-cut materials based on Waspaloy. Advances in Mechanical Engineering 8, 1687814016647888 (2016). 
15. D. Jianxin, S. Wenlong, Z. Hui, Design, fabrication and properties of a self-lubricated tool in dry cutting. International Journal of Machine Tools and Manufacture 49, 66-72 (2009).

16. T. Stefánsson, Application of Cryogenic Coolants in Machining Processes: State-ofthe-art Literature Study and Experimental Work on Metal Matrix Composite. (2014).

17. U.M.R. Paturi, Y.R. Maddu, R.R. Maruri, S.K.R. Narala, Measurement and Analysis of Surface Roughness in WS 2 Solid Lubricant Assisted Minimum Quantity Lubrication (MQL) Turning of Inconel 718. Procedia CIRP 40, 138-143 (2016).

18. R. Westergård, A. Åhlin, N. Axen, S. Hogmark, Sliding wear and friction of Si3N4SiC-based ceramic composites containing hexagonal boron nitride. Proceedings of the Institution of Mechanical Engineers, Part J: Journal of Engineering Tribology 212, 381-387 (1998).

19. Y. Wang, F. Worzala, A. Lefkow, Friction and wear properties of partially stabilized zirconia with solid lubricant. Wear 167, 23-31 (1993).

20. A. Gangopadhyay, S. Jahanmir, Friction and Wear Characteristics of Silicon NitrideGraphite and Alumina-Graphite Composites ${ }^{C}$. Tribology transactions 34, 257-265 (1991). 